\title{
Effectiveness of an intensive care unit family education intervention on delirium knowledge: a pre-test post-test quasi- experimental study
}

\section{Efficacité d'une intervention de formation familiale à l'unité de soins intensifs sur les connaissances concernant le delirium : une étude quasi expérimentale pré-test post-test}

\author{
Karla D. Krewulak, PhD • Margaret J. Bull, PhD, RH • E. Wesley Ely, MD, MPH • \\ Judy E. Davidson, DNP, RN, FCCM, FAAM • Henry T. Stelfox, MD, PhD • \\ Kirsten M. Fiest, PhD
}

Received: 5 March 2020/Revised: 3 June 2020/Accepted: 23 June 2020/Published online: 21 September 2020

(C) The Author(s) 2020

\begin{abstract}
Purpose To create, validate, and refine an intensive care unit (ICU) delirium education intervention to prepare family members to partner with the ICU care team to detect delirium symptoms and prevent and manage delirium using nonpharmacological strategies.

Methods In this pre-test post-test quasi-experimental study, consecutive eligible family members of critically ill patients admitted to an ICU completed an ICU Family Education Delirium intervention in two parts: 1) six-minute video on ICU delirium (risk factors, prevention/management, symptoms, communication with the ICU care team), and 2) two case vignettes to practice detecting delirium using family-administered delirium
\end{abstract}

\section{K. D. Krewulak, $\mathrm{PhD}$}

Department of Critical Care Medicine, Alberta Health Services\& University of Calgary, Ground Floor, McCaig Tower, 3134

Hospital Drive NW, Calgary, AB T2N 5A1, Canada

M. J. Bull, PhD, RH

College of Nursing, Marquette University, Milwaukee, WI, USA

E. Wesley Ely, MD, MPH

Tennessee Valley Veteran's Affairs Geriatric Research Education Clinical Center (VA GRECC), Critical Illness, Brain Dysfunction, and Survivorship (CIBS) Center, Vanderbilt

University Medical Center, Nashville, TN, USA

J. E. Davidson, DNP, RN, FCCM, FAAM

Department of Education, Development and Research,

University of California, San Diego Health, San Diego, CA, USA detection questionnaires (Family Confusion Assessment Method [FAM-CAM] and Sour Seven). Family members' delirium knowledge was measured before, immediately after, and two weeks following the intervention using the Caregiver ICU Delirium Knowledge Questionnaire (CIDKQ).

Results Of 99 family members recruited over eight months, 81 (82\%) completed the intervention and 63 (63/ $81,78 \%$ ) completed all follow-up questionnaires. Family members' delirium knowledge improved significantly following the intervention (pre-CIDKQ, 14; $95 \%$ confidence interval [CI], 13 to 15; post-CIDKQ, 17; 95\% $C I, 16$ to $17 ; P<0.001)$ and was retained two weeks after the intervention (CIDKQ 16; 95\% CI, 16 to 17; P<0.001).

H. T. Stelfox, MD, PhD

Department of Critical Care Medicine, Alberta Health Services\& University of Calgary, Ground Floor, McCaig Tower, 3134

Hospital Drive NW, Calgary, AB T2N 5A1, Canada

Department of Community Health Sciences \& O'Brien Institute for Public Health, University of Calgary, Calgary, AB, Canada

K. M. Fiest, $\mathrm{PhD}(\bowtie)$

Department of Critical Care Medicine, Alberta Health Services\& University of Calgary, Ground Floor, McCaig Tower, 3134

Hospital Drive NW, Calgary, AB T2N 5A1, Canada

e-mail: kmfiest@ucalgary.ca

Department of Community Health Sciences \& O'Brien Institute for Public Health, University of Calgary, Calgary, AB, Canada

Department of Psychiatry \& Hotchkiss Brain Institute, Cumming School of Medicine, University of Calgary, Calgary, AB, Canada 
This included increased knowledge regarding delirium risk factors (e.g., medication, mechanical ventilation), prevention/management (e.g., orientation, day/night routine), and symptoms of delirium. More family members correctly detected delirium symptoms in case vignettes using the Sour Seven (92\%) compared with the FAM-CAM (78\%).

Conclusions $A$ video-based ICU delirium education intervention is effective in educating family members about prevention, detection, and management of delirium.

\section{Résumé}

Objectif Notre objectif était de créer, valider et améliorer une intervention de formation sur le delirium à l'unité de soins intensifs (USI) afin de préparer les membres de la famille à coopérer avec l'équipe de soins de l'USI pour dépister les symptômes de delirium ainsi que prévenir et prendre en charge le delirium à l'aide de stratégies non pharmacologiques.

Méthode Dans cette étude quasi expérimentale avant après, les membres éligibles consécutifs de familles de patients en état critique admis dans une USI ont pris part à une formation familiale sur le delirium à deux volets : 1) le visionnement d'une vidéo de six minutes sur le delirium à l'USI (facteurs de risque, prévention/prise en charge, symptômes, communication avec l'équipe de soins de l'USI), et 2) deux vignettes pour pratiquer le dépistage du delirium à l'aide de questionnaires de dépistage du delirium administrés par la famille (Méthode d'évaluation de la confusion par la famille [FAM-CAM] et Questionnaire de dépistage du delirium 'Sour Seven'). Les connaissances sur le delirium des membres de la famille étaient mesurées avant, immédiatement après et deux semaines après l'intervention à l'aide d'un Questionnaire sur les connaissances des aidants concernant le délirium à l'USI (CIDKQ).

Résultats Parmi les 99 membres de famille recrutés au cours d'une période de huit mois, 81 (82\%) ont complété l'intervention et 63 (63/81, $78 \%)$ ont complété tous les questionnaires de suivi. Les connaissances des membres de la famille sur le delirium se sont significativement améliorées après l'intervention (pré-questionnaire, 14; intervalle de confiance [IC] 95\%, 13 à 15; postquestionnaire, 17; IC 95\%, 16 à 17; $P<0,001)$ et étaient retenues deux semaines après l'intervention (questionnaire 16; IC $95 \%, 16$ à 17; P $<$ 0,001). Cette amélioration était notable dans les catégories de connaissances en matière de facteurs de risque de delirium (par ex., la médication, la ventilation mécanique), de prévention et de prise en charge (par ex., l'orientation, la routine jour/nuit), et des symptômes de delirium. Un nombre plus élevé de membres des familles est parvenu à dépister correctement les symptômes de delirium dans les vignettes à l'aide du questionnaire Sour Seven (92\%) comparativement au FAM-CAM (78\%).

Conclusion Le visionnement d'une vidéo de formation sur le delirium à l'USI est efficace pour former les membres des familles quant à la prévention, le dépistage et la prise en charge du delirium.

Keywords Delirium education · Family · Critical care . Intensive care unit

One challenge in the care of critically ill patients is delirium, an acute confusional state characterized by an acute onset or fluctuating course, attention deficits, and disorganized thinking. ${ }^{1}$ Delirium affects nearly half of patients in the intensive care unit $(\mathrm{ICU})^{2-4}$ and is associated with adverse outcomes in critically ill patients (longer ICU/hospital stay, increased mortality, and cognitive impairment after discharge $)^{5}$ and in family members who witness symptoms of delirium (emotional distress and feelings of anxiety and helplessness). ${ }^{6-8}$ Previous studies report that family participation in patient care is acceptable to patients and their family members, and that families report fewer symptoms of anxiety and depression and increased satisfaction with care following participation..$^{9-11}$ Published guidelines for family-centred care include the provision of family support through family education programs, which show beneficial effects for ICU family members by reducing anxiety, depression, and post-traumatic stress disorder. ${ }^{12}$ Herein lies an opportunity for families to participate in delirium prevention, detection, and management. Although previous research has shown that family members of critically ill patients want to assist with nonpharmacological delirium prevention activities, ${ }^{13,14}$ most families lack adequate delirium knowledge to be effective partners.

Family members of critically ill patients are knowledgeable about the pre-ICU mentation, routines, preferences, and signs of discomfort of their loved ones. As such, a family member educated about ICU delirium may be a useful resource for detecting delirium symptoms and preventing and managing delirium using nonpharmacological strategies, preparing them to partner with the ICU care team in delirium-centred patient care. Family education through leaflets or informational videos has been identified as a strategy to reduce registered nurse (RN)-led education regarding patient care activities, thus minimizing additional burden that would otherwise be placed on nursing staff. ${ }^{15-17}$ The objective of this study was to evaluate the effectiveness of an ICU Family Education on Delirium (iFAM-ED) intervention that prepares family members to partner with the ICU care team to detect delirium symptoms and prevent and manage delirium using nonpharmacological strategies. 


\section{Methods}

The study was approved by the Conjoint Health Research Ethics Board at the University of Calgary (reference number: REB18-0331) in April 2018. Written informed consent was acquired from each family participant. Using a pre-test post-test quasi-experimental study design, the study was conducted between 14 January and 31 October 2019 using a convenience sample of family members of critically ill patients admitted to the 28-bed general systems adult ICU at Foothills Medical Centre in Calgary, Canada (catchment population 1.8 million). Family members eligible for inclusion were adults $(\geq 18 \mathrm{yr}$ ) who could provide informed consent and understand English. More than one family member per patient could participate.

A research assistant approached eligible family members to participate using a script that included the general requirements of informed consent and a standardized description of delirium. Baseline questionnaires were completed after enrollment and in the presence of the study team. Baseline questionnaires included paper versions of a demographic questionnaire (relationship to patient, date of birth, sex, gender, ethnicity, and educational background), the Generalized Anxiety Disorder-seven (GAD-7) ${ }^{18}$ scale, and the previously validated Caregiver ICU Delirium Knowledge Questionnaire (CIDKQ) ${ }^{19}$ to quantify their baseline knowledge of delirium.

\section{Intervention}

The ICU Family Education on Delirium (iFAM-ED) intervention was developed based on a study that educated family members to recognize delirium symptoms in older adults ${ }^{20}$ and adapted for critically ill adults using relevant ICU delirium ${ }^{5,21-23}$ and family delirium education literature..$^{5,20,21,24-26}$ A multidisciplinary team including patient partners (i.e., past ICU patients and family members who are part of our research team), delirium researchers, physicians, and members of a delirium working group (RNs, pharmacist, allied health) iteratively reviewed the iFAM-ED intervention. The intervention included two parts: 1) a six-minute iFAM-ED video module (script found in Appendix 1) and 2) previously validated case vignettes of hypothetical ICU patients (Appendix 2). The iFAM-ED video module included a definition of delirium, a description of the possible symptoms of delirium, delirium risk factors, symptoms that distinguish delirium from dementia, nonpharmacological treatments to prevent and manage delirium, and how to communicate delirium symptoms to the ICU care team. The iFAM-ED video module was presented at a grade six reading level (FleschKincaid grade level). It was assessed for understandability independently by two research assistants (unfamiliar with the study) using the Patient Education Materials Assessment tool for audiovisual materials (PEMAT-A/ V). ${ }^{27}$ The iFAM-ED video module met the criteria for understandability and actionability with scores of $85 \%$ and $100 \%$, respectively (wherein a score of $\geq 70 \%$ is considered understandable or actionable). ${ }^{28}$ The iFAMED case vignettes selected for each participating family member were case-matched for the patient's age category, sex, and reason for admission and randomly selected for which features of delirium were present/absent for a total of 80 unique case vignettes (Table 1). After watching the iFAM-ED video module, family members practiced detecting delirium in the provided case vignettes using two family-administered delirium detection questionnaires: the Family Confusion Assessment Method (FAM-CAM) ${ }^{29}$ and Sour Seven. ${ }^{30}$ Each case vignette was evaluated for the four features of delirium: inattention (feature 1), sudden onset or fluctuating course (feature 2), altered level of consciousness (feature 3), and disorganized thinking (feature 4). If features 1,2 and either 3 or 4 were present, the hypothetical patient had delirium. ${ }^{1,31,32}$

Family members were given a choice to complete the iFAM-ED module at their convenience using their own devices, or while at the bedside using a study tablet or following along with a printed booklet while a research assistant read the video script. Directly following the iFAM-ED intervention, the family member completed the CIDKQ again to quantify any immediate change in delirium knowledge. To quantify the short-term retention of the knowledge, family members completed an online version of the CIDKQ (generated using Qualtrics survey software, hosted by the University of Calgary [Qualtrics, Provo, UT]) two weeks following provision of the iFAMED intervention (Fig. 1). We used evidence-based cohort retention follow-up protocols to reduce attrition (https:// www.improvelto.com/). ${ }^{33,34}$

\section{Measures}

\section{Caregiver ICU Delirium knowledge questionnaire (CIDKQ)}

A 21-item multiple choice (yes/no/don't know) questionnaire was used to measure family members' knowledge about ICU delirium and to assess the effect of the education provided. The CIDKQ addressed the three dimensions of delirium knowledge: risk factors (items 110), actions (items 11-16) and symptoms (items 17-21). The CIDKQ score ranges from 0 to 21 , with a higher score indicating more ICU delirium knowledge. The internal consistency reliability (Cronbach's alpha) for the CIDKQ is $0.79 .{ }^{19}$ 
Table 1 Case vignettes of hypothetical ICU patients

\begin{tabular}{|c|c|c|c|}
\hline Age category & Biological sex & Reason for admission & Features of delirium \\
\hline$<65 \mathrm{yr}$ & Female & Postoperative & $\begin{array}{l}\text { He does not know that today is Sunday or that he is in the hospital/He knows } \\
\text { he is in the ICU at the hospital and that today is Sunday (disorganized thinking) }\end{array}$ \\
\hline \multirow[t]{4}{*}{$\geq 65 \mathrm{yr}$} & \multirow[t]{4}{*}{ Male } & Respiratory failure & $\begin{array}{l}\text { She seems more tired and falls asleep while you are talking with her/She is awake } \\
\text { and the nurse tells you she had a good sleep last night (altered level of consciousness) }\end{array}$ \\
\hline & & Sepsis & $\begin{array}{l}\text { When he is awake, his eyes seem to wander around the room and he does not } \\
\text { focus on you/He focuses on you the whole time you are telling him about } \\
\text { what happened in the news today (inattention) }\end{array}$ \\
\hline & & Stroke & $\begin{array}{l}\text { She was not like this when you visited her yesterday/ She was like this when } \\
\text { you visited her yesterday, too (sudden onset/fluctuating course) }\end{array}$ \\
\hline & & Trauma & \\
\hline
\end{tabular}

The case vignettes were case-matched for the patients age category, sex, and reason for admission and randomly selected for which features of delirium were present/absent for a total of 80 unique case vignettes. ICU $=$ intensive care unit.

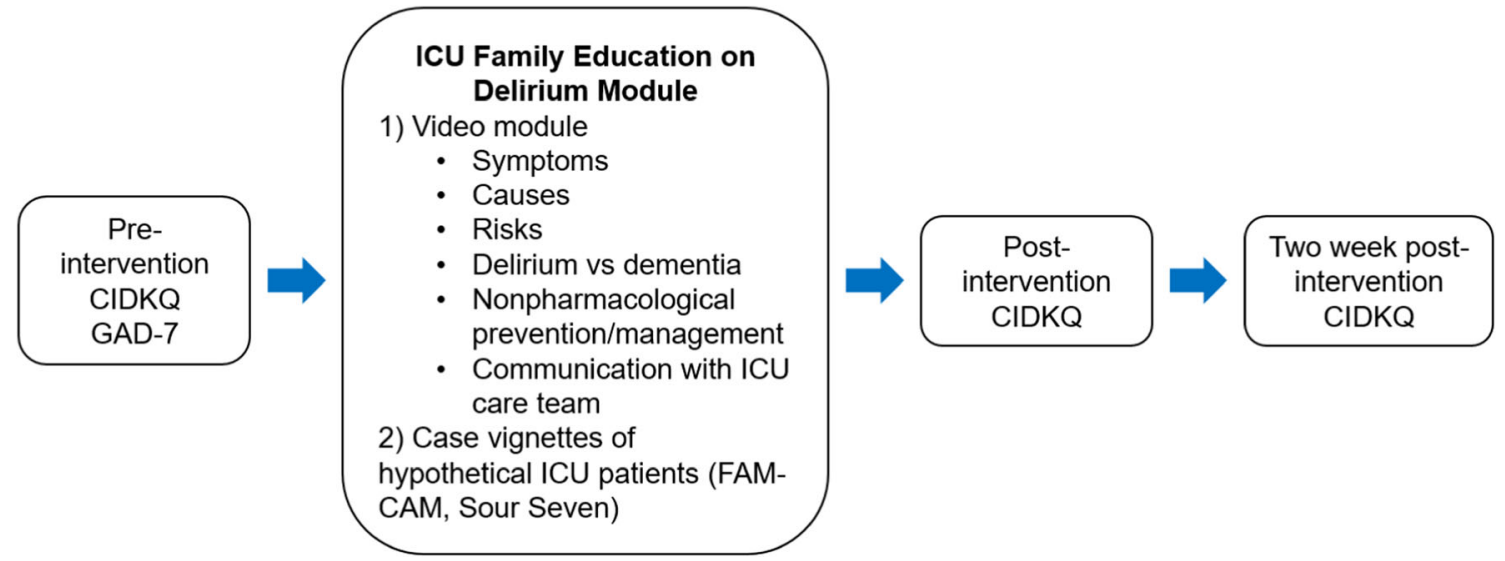

Fig. 1 Schematic of the ICU Family Education on Delirium (iFAM-ED) intervention. ICU = intensive care unit

\section{Family confusion assesement method (FAM-CAM)}

This is an 11-item delirium assessment tool derived from the Confusion Assessment Method ${ }^{1}$ and designed to be administered by family members. ${ }^{29}$ The FAM-CAM is considered positive if the following features are present: acute onset or fluctuating course (questions 1, 9, 10), inattention (question 2), and either disorganized thinking (questions 3,5,6) or altered level of consciousness (question 4). The FAM-CAM was shown to have a high sensitivity $(88 \%)$, specificity $(98 \%)$, and reliability $(\mathrm{k}=0.85)$ in general hospital settings. ${ }^{29}$

\section{Sour seven}

This is a 7-item delirium assessment tool designed to be administered by informal caregivers or untrained nurses. ${ }^{30}$ Sudden disturbances in level of awareness or attentiveness, fluctuations in awareness and attentiveness, and disordered thinking may indicate delirium. Scores $\geq 9$ out of 18 are indicative of delirium and have $100 \%$ positive predictive value in hospitalized seniors. ${ }^{30}$

\section{Generalized anxiety disorder-seven (GAD-7)}

This is a 7-item scale following the DSM-IV criteria for GAD. ${ }^{18}$ The items are scored from 0 (not at all) to 3 (nearly every day) based on the frequency of symptoms, with higher scores indicating more anxiety. A score $\geq 10$ out of 21 is indicative of clinically significant GAD; scores of 5, 10, and 15 represent mild, moderate, and severe levels of anxiety, respectively.

Statistical analysis

Sample size was calculated using pre-test post-test effect size and variance data from a study educating family members of older adults to recognize delirium. ${ }^{20}$ Assuming a $95 \%$ confidence interval $\left(Z_{\alpha}=1.96\right), 80 \%$ power $\left(Z_{\beta}=\right.$ 1.96), standard deviation (SD; $\sigma=8.5$ ) and mean difference $\left(\bar{x}_{\text {post }}-\bar{x}_{\text {pre }}=2.5\right),{ }^{20}$ a minimum sample size of 21 family members was required.

Sample size $=\frac{2 \times\left(Z_{\alpha}+Z_{\beta}\right)^{2} \times \sigma^{2}}{\left(\bar{x}_{\text {post }}-\bar{x}_{\text {pre }}\right)^{2}}$ 


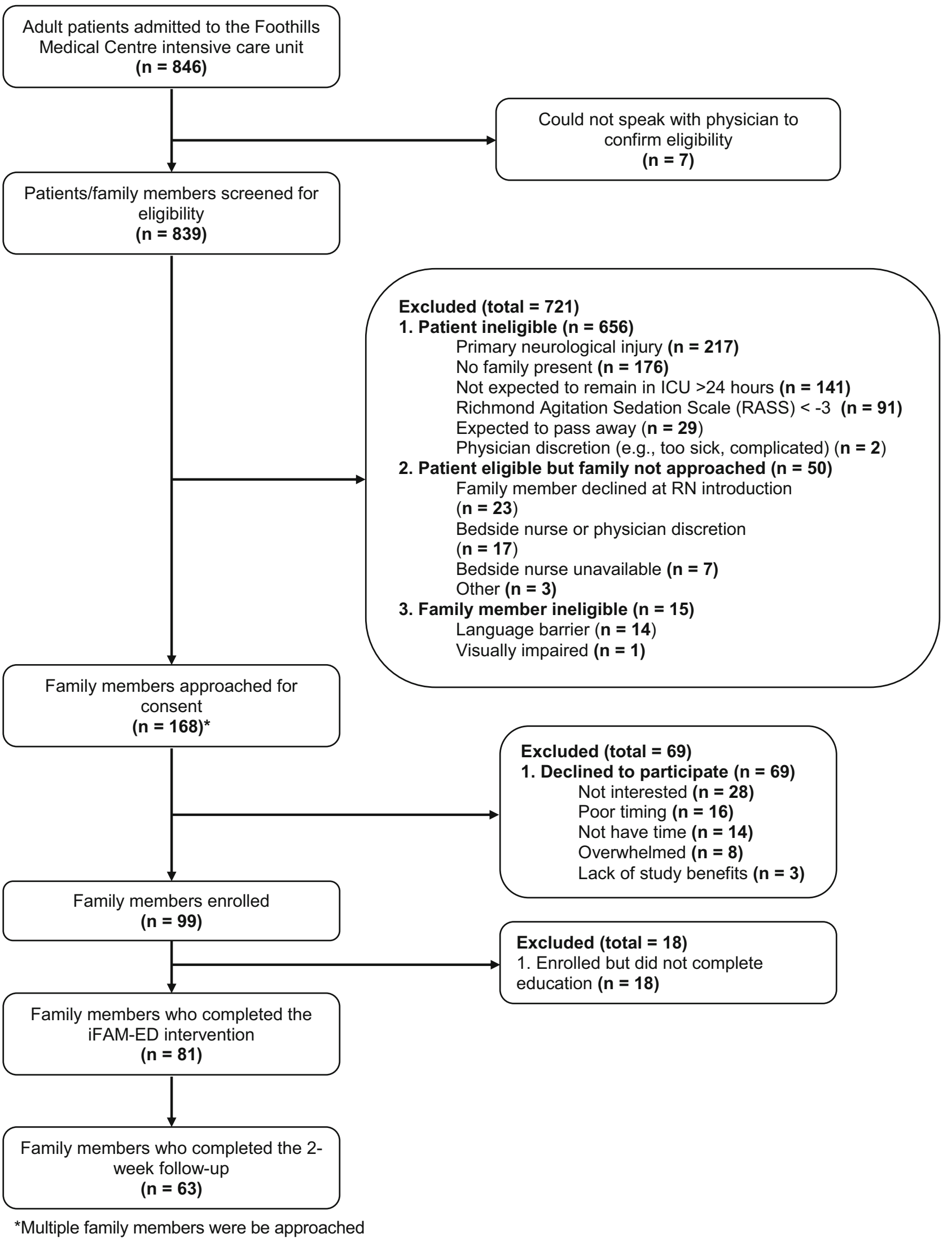

Fig. 2 Participant flow 
Data analysis was conducted using Stata version 14 (StataCorp., College Station, TX, USA). Descriptive statistics were examined for all study variables as mean, median, or number and percentage, where appropriate. Paired $t$ tests (pre-test/post-test, pre-test/two weeks post-test) were used to examine the difference in delirium knowledge (i.e., CIDKQ score) before and after the iFAM-ED module. A $P<0.05$ was considered statistically significant. Kappa was calculated as a measure of agreement between the family-administered delirium detection using the FAMCAM or Sour Seven and the true delirium status in each case vignette (the reference standard), wherein agreement was interpreted as fair (0.21-0.40), moderate (0.41-0.60), substantial (0.61-0.80), and almost perfect $(0.81-1.00){ }^{35}$ We analyzed GAD-7 and CIDKQ scores as continuous (GAD-7: 0-15, CIDKQ: 0-21) and categorical (GAD-7: < 10 or $\geq 10$ [clinically significant GAD]; CIDKQ: $<$ mean or

Table 2 Characteristics of family members who completed the full study

\begin{tabular}{lc}
\hline Characteristic & $n=63$ \\
\hline Relationship to patient, $n(\%)$ & $22(35)$ \\
Child & $24(38)$ \\
Spouse & $8(13)$ \\
Parent & $5(8)$ \\
Other & $4(6)$ \\
Sibling & \\
Education, $n(\%)$ & $14(22)$ \\
High school or less & $45(71)$ \\
More than high school & $4(6)$ \\
Other & $43(68)$ \\
Female gender, $n(\%) *$ & $50.8(14.5 ; 22-79)$ \\
Age, mean (SD; range) yrs & \\
Generalized anxiety disorder scale, $n(\%)$ & $20(32)$ \\
Minimal (score 0-4) & $24(38)$ \\
Mild (score 5-9) & $14(22)$ \\
Moderate (score 10-14) & $5(8)$ \\
Severe (score > 15) & $19(30)$ \\
Clinically significant anxiety, $n(\%)$ & \\
\hline
\end{tabular}

*Sex and gender were recorded for each participant. The proportion for female sex and gender are the same, as such only sex is displayed in the table. $\mathrm{SD}=$ standard deviation $\geq$ mean) variables. We used Pearson correlation coefficients to evaluate the correlation between GAD-7 and CIDKQ as continuous variables, wherein a Pearson r value of $0.10,0.30$, or 0.50 was interpreted as small, medium, and large effect sizes, respectively. ${ }^{36}$

\section{Results}

Between 14 January and 31 October 2019, 99 family members were recruited, with a participation rate of $59 \%$ (99/168) (Fig. 2). Family members had a mean (SD) age of 50.8 (14.5) yr, were mostly female $(43 / 63,68 \%)$, and were most commonly the spouse $(24 / 63,38 \%)$ (e.g., husband, wife) or adult children $(22 / 63,35 \%)$ of the patient (Table 2). Most family members experienced mild (38\%, $24 / 63)$ or clinically significant $(30 \%, 19 / 63)$ symptoms of anxiety. There was no correlation between symptoms of anxiety and delirium knowledge when analyzed as binary variables $(P=0.872)$ or continuous variables (Pearson correlation coefficient $<0.10)$.

Of the 99 enrolled family members, 81 completed the iFAM-ED intervention $(81 / 99,82 \%)$ and 63 completed all questionnaires at two-week follow-up (63/81, 78\%). Most family members $(73 / 99,74 \%)$ used the study tablet to watch the iFAM-ED video module. Of the 24 family members who chose to watch the iFAM-ED video module on their own device, 37\% (9/24) completed the iFAM-ED intervention. Completion of the iFAM-ED intervention and associated questionnaires took about $20 \mathrm{~min}$ and no families reported being overwhelmed by their participation in the study.

Family members' ICU delirium knowledge improved significantly $(P<0.001)$ following provision of the iFAMED intervention (pre-CIDKQ, 13.8; 95\% CI, 13.0 to 14.6; post-CIDKQ, $16.7 ; 95 \% \mathrm{CI}, 16.3$ to $17.2 ; P<0.001)$ and was retained two weeks after the intervention (CIDKQ two weeks, 16.4; 95\% CI, 15.8 to $17.1 ; P<0.001$ ) (Table 3). Family members' knowledge of the three dimensions of ICU delirium (risk, actions, and symptoms) also improved significantly $(P<0.001)$ (Table 3$)$. This included improvement in knowledge of delirium risk factors, actions to prevent/manage delirium, and the ability to distinguish between symptoms of dementia and delirium (Table 4).

Table 3 Delirium knowledge before, immediately after, and two weeks after the iFAM-ED module $(n=63)$

\begin{tabular}{lccc}
\hline Delirium knowledge & Pre-test & Post-test & Two weeks after test \\
\hline Total (0-21) & $13.8(13.0$ to 14.6$)$ & $16.7(16.3$ to 17.2$)$ & $16.4(15.8$ to 17.1$)$ \\
Risks (0-10) & $6.7(6.3$ to 7.2$)$ & $7.6(7.3$ to 7.8$)$ & $8.3(8.1$ to 8.6$)$ \\
Actions (0-6) & $4.4(4.0$ to 4.7$)$ & $5.3(5.1$ to 5.5$)$ & $5.3(5.1$ to 5.5$)$ \\
Symptom (0-5) & $2.7(2.4$ to 3.0$)$ & $3.9(3.6$ to 4.1$)$ & $3.7(3.4$ to 4.1$)$ \\
\hline
\end{tabular}

data are represented as the mean (95\% confidence inteval) as indicated 
Table 4 Items of the Caregiver ICU Delirium Knowledge Questionnaire (CIDKQ) correctly answered before, immediately after, and two weeks after the iFAM-ED module $(n=63)$

\begin{tabular}{|c|c|c|c|}
\hline $\begin{array}{l}\text { Item Description } \\
\text { number }\end{array}$ & $\begin{array}{l}\text { Pre- } \\
\text { intervention }\end{array}$ & $\begin{array}{l}\text { Immediately } \\
\text { post-intervention }\end{array}$ & $\begin{array}{l}\text { Two weeks } \\
\text { post- } \\
\text { intervention }\end{array}$ \\
\hline & $\begin{array}{l}\text { Correctly } \\
\text { answered, } n \\
(\%)\end{array}$ & $\begin{array}{l}\text { Correctly } \\
\text { answered, } n(\%)\end{array}$ & $\begin{array}{l}\text { Correctly } \\
\text { answered, } n(\%)\end{array}$ \\
\hline
\end{tabular}

\section{Risk subgroup}

Do you think any of the patients below might be at risk for delirium?

$\begin{array}{llrrr}1 & \text { Patients who are older } & 51(81) & 60(95) & 59(94) \\ 2 & \text { Patients who are married (vs not married) } & 19(30) & 34(54) & 35(56) \\ 3 & \text { Patients with dementia } & 58(92) & 45(71) & 49(78) \\ 4 & \text { Patients with an infection } & 57(92) & 60(95) & 61(97) \\ 5 & \text { Patients with more than high school education } & 23(36) & 33(52) & 25(40) \\ 6 & \text { Patients who had recent surgery } & 61(97) & 62(98) & 62(98) \\ 7 & \text { Patients who are dehydrated } & 54(86) & 59(94) & 58(92) \\ 8 & \text { Patients experiencing change in surroundings such as admission to a hospital or } & 54(84) & 63(100) & 60(95) \\ & \quad \text { change to another part of the hospital } & 54(86) & 63(100) & 59(94) \\ 9 & \text { Patients who are mechanically ventilated or intubated } & 48(76) & 61(97) & 58(92)\end{array}$

\section{Action subgroup}

If your family member had sign of sudden confusion, would you

$11 \quad$ Orient patient to time and day and bring in photos from home $51(81) \quad 62(98)$

$12 \quad$ Wait $24 \mathrm{hr}$ to see if the person got better $39(62) \quad 48$ (76)

13 Let the patient sleep during the day to recover $\quad 18(29) \quad 39(62) \quad 40(63)$

14 Do nothing $\quad 57(90) \quad 62(98) \quad 60(95)$

$15 \quad$ Inform the bedside RN or another member of the care team right away $58(92) \quad 63(100)$

$16 \quad$ Ask the care team about medication changes $\quad 52(82) \quad 60(95) \quad 63(100)$

\section{Symptom subgroup}

Do you think any of the patients described below might have delirium?

17 Patient slowly becomes more confused over a few months, is forgetful, has trouble paying attention, and is more confused later in the day

18 Patient slowly becomes more confused over a few months, is forgetful, has trouble paying attention, and later in the day sees things that are not there

$\begin{array}{lll}21(33) & 37(59) & 41(65) \\ 7(11) & 31(49) & 34(54) \\ 59(94) & 62(98) & 60(95)\end{array}$
19 Patient suddenly becomes confused over a few days or hours, floats in and out of
confusion during the day, has trouble paying attention, sees things that are not
there

20 Patient suddenly becomes confused over a few days or hours, has trouble paying 47 (75) attention, and sleeps more during the day

$\begin{array}{ll}62(98) & 57(90) \\ 51(81) & 42(67)\end{array}$

21 Patient becomes more confused over a few days and suddenly has trouble getting 37 (59) to the bathroom on time

$R N$ registered nurse.

After watching the iFAM-ED video module, family members correctly classified delirium in $78 \%$ (95\% CI, 69 to 85 ) and $92 \%$ (95\% CI, 86 to 96 ) of the provided case vignettes using the FAM-CAM or Sour Seven, respectively. The agreement between the family member's detection of delirium in the case vignette was moderate using the FAM-CAM (kappa $=0.44)$ and substantial using the Sour Seven $(\mathrm{kappa}=0.75)$. The features of delirium presented in the case vignettes that family members frequently missed were altered level of consciousness
("He seems more tired and falls asleep while you are talking with him") and disorganized thinking ("He does not know that today is Sunday or that he is in the hospital") (Table 5).

\section{Discussion}

The current study showed that provision of the iFAM-ED intervention effectively improves family members' ICU 
Table 5 Proportion of family members who correctly identified the features of delirium in the provided case vignettes $(n=63)$

\begin{tabular}{llr}
\hline Feature of delirium & FAM-CAM, $n(\%)$ & Sour Seven, $n(\%)$ \\
\hline Suddent onset, fluctuating course & $105(83)$ & $102(81)$ \\
Inattention & $106(84)$ & $116(92)$ \\
Altered level of consciousness & $94(75)$ & $76(60)$ \\
Disorganized thinking & $87(69)$ & $79(63)$
\end{tabular}

FAM-CAM Family confusion assessment method

delirium knowledge. More participants recognized ICU delirium risk factors (new medication, mechanical ventilation, change in surroundings), actions (patient orientation, sleep/wake cycle), and symptoms (sudden confusion). This included $78 \%$ and $92 \%$ of participants correctly classifying delirium in the provided case vignettes using the FAM-CAM and Sour Seven, respectively. Furthermore, family members showed shortterm retention of their ICU delirium knowledge.

Several studies have reported family member delirium education in cardiac surgery, ${ }^{37}$ hospitalized older adults, $^{24,26}$ or palliative care $^{38-40}$ populations. We compared the effectiveness of the iFAM-ED intervention with the delirium education intervention provided to family members of elective hip and knee surgery patients in the study by Bull et al. ${ }^{20}$ Similarly to the study by Bull et al., our study showed a statistically significant improvement in delirium knowledge scores from pre-intervention to two weeks post-intervention. ${ }^{20}$ Since knowledge is maintained after two weeks, family members may better detect delirium onset after their loved ones are discharged from the ICU (e.g., hospital ward, home). In contrast to our iFAM-ED intervention, the delirium education intervention in the study by Bull et al. was telephone-based and was delivered to family members by a nurse over a period of three weeks prior to their loved ones' hospital admission (given the elective nature of their admission). The current study employed a short, video-based intervention that included comparable content to the Bull study, but was just as effective in a shorter amount of time (time to complete: $20 \mathrm{~min}$ as opposed to three weeks).

The iFAM-ED intervention has several benefits for educating family members of critically ill patients on detecting delirium symptoms and preventing and managing delirium using nonpharmacological strategies. Previous studies have shown that families benefit from the provision of understandable and consistent information. ${ }^{41-43}$ The current study supports the provision of understandable, consistently presented ICU delirium education. The iFAMED intervention was understandable; it was presented at a grade six reading level (as recommended by the National Institutes of Health and the American Medical Association), ${ }^{44,45}$ was created by a multidisciplinary team (including patient and family partners), and scored $85 \%$ ( $\geq$
75\% considered understandable) on the PEMAT-A/V tool. In a clinical setting, the iFAM-ED intervention is videobased and, as such, is a more consistent method for presenting ICU delirium education than nurse-provided ICU delirium education interventions that may vary in delivery and content and, based on nurse workload, may not be consistently provided.

Further refinement of the iFAM-ED intervention could improve a family member's ICU delirium knowledge and ability to identify symptoms of delirium. For instance, after the iFAM-ED intervention, more participants distinguished symptoms of delirium from symptoms of dementia, but fewer participants identified dementia as a risk factor for delirium. It is possible that, after the iFAM-ED intervention, participants viewed delirium and dementia as two separate syndromes that could not occur concurrently. Further refinement of the iFAM-ED intervention could include an explanation of delirium superimposed on dementia. Family members who understand the difference between delirium and dementia may be helpful partners or resources to the ICU care team to recognize delirium superimposed on dementia. ${ }^{46}$

Further refinement of the iFAM-ED intervention could include additional description of disorganized thinking, (e.g., "This person acts different than they did before they were admitted to the ICU" or "If you ask this person a question, they may reply with an answer that does not make sense") to improve family member's identification of disorganized thinking in provided case vignettes. In addition, the readability of the FAM-CAM (FleschKinkaid reading level $\sim 11^{\text {th }}$ grade) and the Sour Seven (Flesch-Kinkaid reading level $\sim 12^{\text {th }}$ grade) are higher than the suggested grade six level. Efforts to improve the readability of the FAM-CAM and Sour Seven may improve family member's understanding of the questionnaires and may improve their identification of disorganized thinking and altered level of consciousness.

A recent qualitative study reported that family members wish to be involved with nonpharmacological delirium prevention, but would like delirium education at the beginning of the patient's stay. ${ }^{13}$ Nevertheless, this may not be the case for all family members, who may feel stressed or overwhelmed when first introduced to the ICU environment. A video-based ICU delirium education 
intervention provides families an opportunity to engage, decline, or defer their participation in delirium prevention, detection, and management. This flexibility is an important consideration for any family education intervention because, as with all family engagement strategies, participation in patient care may not be desired by all family members (or patients). Another benefit of videobased ICU delirium education is that it allows families to watch the video on their own time or multiple times. Although the current study showed that video-based ICU delirium education was effective on its own, previous studies report that family members find communication with the bedside RN to be important. ${ }^{13,14,47,48}$ As such, video-based delirium education should be accompanied by ICU care team engagement. This need was illustrated by the small proportion of family members who completed the iFAM-ED module on their own, using their own device, compared with family members who used the study tablet with a research assistant nearby to answer any questions.

There were several limitations of this study. First, the study was conducted in one ICU located at an academic centre. Upon entry to the ICU, as standard of care, the family is provided a pamphlet on delirium (risk factors, symptoms, and actions). The ICU regularly screens for delirium using the Intensive Care Delirium Screening Checklist ${ }^{49}$ and discusses delirium at multidisciplinary rounds. As such, these results may not be generalizable to family members in other ICUs with different processes for delirium screening, monitoring, and management. Second, the current study may not be representative of family members who were overwhelmed or were highly anxious and declined to participate or did not complete all follow-up. Third, the current study lacked a control group. A future randomized-controlled trial is needed to compare the effects of the iFAM-ED intervention with a family-group who receives no education on delirium and ability to detect delirium symptoms in their loved one. Despite these limitations, the current study has several strengths. First, the iFAM-ED intervention was created together with a multidisciplinary team, including patient and family partners. Although the study occurred at a single centre, Foothills Medical Centre serves a diverse population with a catchment area of 1.8 million. Family-administered delirium detection, prevention, and management is not a replacement for established delirium screening, monitoring, and management, but may be helpful in settings with limited nurse staffing resources or where healthcare providers do not have familiarity with a patient's cognitive status prior to admission. ${ }^{50}$

\section{Conclusions}

A video-based ICU delirium education intervention was effective in educating family members of critically ill patients on the detection of delirium symptom and the prevention and management of delirium using nonpharmacologic strategies. This delirium education may act as a primer for family members to partner with the ICU care team in delirium-related patient issues or empower family members to participate in deliriumfocused discussions. This study supports future research evaluating whether ICU delirium education improves family members' ability to detect symptoms of delirium and to prevent and manage delirium in their loved one during their ICU stay or if family participation in delirium prevention and management improves patient outcomes.

Acknowledgements The authors thank Bonnie Sept, a patient partner, for her help in reviewing study materials. The authors also thank Katherine Liu and Israt Yasmeen for their help in enrolling participants. This study was supported by a grant to Henry T. Stelfox from the Canadian Institutes of Health Research.

Authorship contributions All authors made substantial contributions to this work. Karla D. Krewulak, Henry T. Stelfox, and Kirsten M. Fiest designed the study. Karla D. Krewulak facilitated acquisition of data and performed the data analysis. Karla D. Krewulak, Margaret J. Bull, Henry T. Stelfox, E. Wesley Ely, and Kirsten M. Fiest interpreted the data; Karla D. Krewulak drafted the manuscript. The authors have no conflicts of interest relevant to this manuscript.

\section{Disclosures None.}

Funding statement This work was supported by a Canadian Institutes of Health Research Grant (to HTS). The funders had no role in study design, data collection and analysis, decision to publish, or preparation of the manuscript.

This study is not registered in a public registry of clinical trials.

Editorial responsibility This submission was handled by Dr. Sangeeta Mehta, Associate Editor, Canadian Journal of Anesthesia.

Open Access This article is licensed under a Creative Commons Attribution-NonCommercial 4.0 International License, which permits any non-commercial use, sharing, adaptation, distribution and reproduction in any medium or format, as long as you give appropriate credit to the original author(s) and the source, provide a link to the Creative Commons licence, and indicate if changes were made. The images or other third party material in this article are included in the article's Creative Commons licence, unless indicated otherwise in a credit line to the material. If material is not included in the article's Creative Commons licence and your intended use is not permitted by statutory regulation or exceeds the permitted use, you will need to obtain permission directly from the copyright holder. To view a copy of this licence, visit http://creativecommons.org/licenses/ by-nc/4.0/.

\section{Appendix 1: ICU Family Education on Delirium (iFAM-ED) video module script}


iFAM-ED video module script

The use of the script is important to standardize how the educational module is being presented to the family caregivers. If the module is given in person (i.e., instead of electronically) this script should be memorized. It should be made clear up front that any questions will be answered at the end to not affect the consistent provision of the intervention.

[Start Script]

\{Title Slide\}

Delirium is a brain condition common in ICU patients that affects the way a patient thinks.

Nearly half of the patients in intensive care units suffer from delirium during their ICU stay.

Delirium may be hard to detect, but you, the family caregiver, may be the first to notice small changes in thinking in your loved one.

There are ways that you can help to prevent and manage delirium.

Your help may stop delirium from happening, reduce how long the delirium lasts, or how severe the delirium is.

Before you can help prevent and manage delirium, this short video will tell you about the signs of delirium, who is at risk, and what you can do to prevent and manage delirium.

You can use the information from this video not only in the ICU but also throughout your loved ones' hospital stay.

\{Turn page\}

Here are some signs of delirium you should look for:

A person with delirium:

-cannot pay attention. This person is easily distracted or, when you speak with them, cannot focus on the conversation.

-may have trouble thinking clearly. For instance, they may not know where they are, forget who you are or do not understand what is going on around them.

-have sudden changes in mood and behavior.

-have changes in sleep such as sleeping all of the time or being more tired than usual.

-They may see or hear things that are not there. These things they see or hear feel very real to them.

-Patients who have delirium may be agitated or upset OR drowsy or quiet.

\{Turn page\}

It is important to know what may cause delirium. These include:

-stress 
-dehydration

-medical illness

-infection

-surgery

-a change in patient location such as admission to a hospital or transfer to another unit

-medications. Some medications that help a patient's underlying medical condition may also

cause delirium

-malnutrition

-pain or fever

\{Turn page\}

It is also important to know who is at increased risk for delirium?

-Older patients. Studies show that patients 65 years of age and older are at increased risk of delirium.

-Patients who have dementia

-Patients who are mechanically ventilated, which means they require machines to help them to breathe.

\{Turn page\}

Delirium sounds a lot like dementia, but there are a number of key differences:

-Delirium develops suddenly (changes happen over hours, days, or weeks). Dementia develops slowly (changes happen over months or years).

-Delirium usually improves and can come and go. Nevertheless, dementia does not improve and gets worse over time.

-Delirium can be caused by illness or medication. Dementia is rarely caused by illness or medication.

\{Turn page\}

Now that you know about delirium and how to identify it, what can you do to prevent or manage delirium while your loved one is in the ICU or hospital?

1. Bring in photos and items from home. Put these items where they can be easily seen by your loved one.

2. Patients with delirium may be staying awake when they should be asleep OR sleeping when they should be awake. You can help prevent or manage delirium by helping your loved one with a normal sleep pattern. During the day, keep the blinds up and speak with your loved one. At night time, turn the lights off and keep it quiet. To help with sleep, provide sleep aids such as 
ear plugs or maybe a blanket from home.

3. Orient your loved one. This can be done a few ways:

-Speak in a calm, reassuring tone of voice and tell them where they are and why. Do not overdo this as sometimes this question may cause frustration or agitation. Other ways to orient your loved one include:

-Reading the daily news out loud on a subject that is interesting to them.

-Talking about a favourite vacation or meal that you both enjoyed.

Remember that patients who are mechanically ventilated are unable to speak, but they can understand you. Communication can be difficult, so try what works best for your loved one. This may include only asking yes/no questions OR some patients find using a communication board with icons and pictures showing basic needs is helpful. If your loved one can write, give them a pen and paper. If you have an apple phone, download the free app "Small Talk Intensive Care." This is an app that provides picture-based vocabulary of phrases that patients can use to communicate their needs and feelings such as "I want to sit up."

Other ways to prevent and manage delirium are:

4. Playing quiet/calm music that they enjoy.

5. Bringing in their hearing aids and glasses.

6. Asking the bedside nurse about brain games that are available in the unit or if you can help with moving your loved one around.

7. Spread out visitors through the day.

\{Turn page\}

If your loved one seems confused or you see changes in their thinking, tell a member of the ICU care team. For example, you could say:

"Yesterday, my family member was easy to have a conversation with. Today, they are not paying attention and are sleeping more than usual. I think they may have delirium."

\{Turn page\}

"I notice that my family member suddenly is confused. They were not confused this morning.

Are there any changes to their medication that might be causing this?"

\{Turn page\}

Do you think you can identify delirium? Read the descriptions of made up ICU patient given to you by the research team. Complete the two questionnaires to detect whether the patient has delirium or does not have delirium. 


\section{Appendix 2: Example of a case vignette of a hypothetical patient}

Patient: 43 yr old man

Reason for hospitalization: Life-threatening infection (sepsis).

\section{What you observed when you visited your friend or family member today:}

He does not know that today is Sunday or that he is in the hospital. He is awake and the nurse

tells you he had a good sleep last night. When you are talking to him, his eyes seem to wander

around the room and he does not focus on you. He was not like this when you visited him

yesterday. After reading the above case vignette, complete the FAM-CAM and Sour Seven

Questionnaires based on the information contained in the case vignette.

\section{References}

1. Inouye SK, van Dyck CH, Alessi CA, Balkin S, Siegal AP, Horwitz RI. Clarifying confusion: the confusion assessment method. A new method for detection of delirium. Ann Intern Med 1990; 113 : 941-8.

2. Brummel NE, Jackson JC, Pandharipande PP, et al. Delirium in the ICU and subsequent long-term disability among survivors of mechanical ventilation. Crit Care Med 2014; 42: 369-77.

3. Ely EW, Shintani A, Truman B, et al. Delirium as a predictor of mortality in mechanically ventilated patients in the intensive care unit. JAMA 2004; 291: 1753-62.

4. Pandharipande PP, Girard TD, Jackson JC, et al. Long-term cognitive impairment after critical illness. N Engl J Med 2013; 369: 1306-16.

5. Salluh JI, Wang H, Schneider EB, et al. Outcome of delirium in critically ill patients: systematic review and meta-analysis. BMJ 2015; . https://doi.org/10.1136/bmj.h2538.

6. Bull MJ. Delirium in older adults attending adult day care and family caregiver distress. Int J Older People Nurs 2011; 6: 85-92.

7. Schmitt EM, Gallagher J, Albuquerque A, et al. Perspectives on the delirium experience and its burden: common themes among older patients, their family caregivers, and nurses. Gerontologist 2019; 59: 327-37.

8. Partridge JS, Martin FC, Harari D, Dhesi JK. The delirium experience: what is the effect on patients, relatives and staff and what can be done to modify this? Int J Geriatr Psychiatry 2013; 28: 804-12.

9. Azoulay E, Pochard F, Chevret $S$, et al. Family participation in care to the critically ill: opinions of families and staff. Intensive Care Med 2003; 29: 1498-504.

10. Garrouste-Orgeas $M$, Willems V, Timsit JF, et al. Opinions of families, staff, and patients about family participation in care in intensive care units. J Crit Care 2010; 25: 634-40.

11. Wong P, Redley B, Digby R, Correya A, Bucknall T. Families' perspectives of participation in patient care in an adult intensive care unit: a qualitative study. Aust Crit Care 2019; . https://doi. org/10.1016/j.aucc.2019.06.002.

12. Davidson JE, Aslakson RA, Long AC, et al. Guidelines for familycentered care in the neonatal, pediatric, and adult ICU. Crit Care Med 2017; 45: 103-28.
13. Smithburger PL, Korenoski AS, Alexander SA, Kane-Gill SL. Perceptions of families of intensive care unit patients regarding involvement in delirium-prevention activities: a qualitative study. Crit Care Nurse 2017; 37: e1-9.

14. Smithburger PL, Korenoski AS, Kane-Gill SL, Alexander SA. Perceptions of family members, nurses, and physicians on involving patients' families in delirium prevention. Crit Care Nurse 2017; 37: 48-57.

15. Nolen $K B$, Warren NA. Meeting the needs of family members of ICU patients. Crit Care Nurs Q 2014; 37: 393-406.

16. Soury-Lavergne A, Hauchard I, Dray S, et al. Survey of caregiver opinions on the practicalities of family-centred care in intensive care units. J Clin Nurs 2012; 21: 1060-7.

17. Riley BH, White J, Graham S, Alexandrov A. Traditional/ restrictive vs patient-centered intensive care unit visitation: perceptions of patients' family members, physicians, and nurses. Am J Crit Care 2014; 23: 316-24.

18. Spitzer RL, Kroenke K, Williams JB, Lowe B. A brief measure for assessing generalized anxiety disorder: the GAD-7. Arch Intern Med 2006; 166: 1092-7.

19. Krewulak KD, Bull MJ, Ely EW, Stelfox HT, Fiest KM. Psychometric evaluation of the family caregiver ICU delirium knowledge questionnaire. BMC Health Res Serv 2020; . https:// doi.org/10.1186/s12913-020-4892-5.

20. Bull MJ, Boaz L, Maadooliat M, et al. Preparing family caregivers to recognize delirium symptoms in older adults after elective hip or knee arthroplasty. J Am Geriatr Soc 2017; 65: e13-7.

21. Zaal IJ, Devlin JW, Peelen LM, Slooter AJ. A systematic review of risk factors for delirium in the ICU. Crit Care Med 2015; 43: 40-7.

22. Barr J, Fraser GL, Puntillo K, et al. Clinical practice guidelines for the management of pain, agitation, and delirium in adult patients in the intensive care unit. Crit Care Med 2013; 41: 263306.

23. Devlin JW, Skrobik Y, Gelinas $C$, et al. Clinical practice guidelines for the prevention and management of pain, agitation/sedation, delirium, immobility, and sleep disruption in adult patients in the ICU. Crit Care Med 2018; 46: e825-73.

24. Rosenbloom DA, Fick DM. Nurse/family caregiver intervention for delirium increases delirium knowledge and improves attitudes toward partnership. Geriatr Nurs 2014; 35: 175-81. 
25. Inouye SK, Bogardus ST Jr, Charpentier PA, et al. A multicomponent intervention to prevent delirium in hospitalized older patients. N Engl J Med 1999; 340: 669-76.

26. Keyser SE, Buchanan D, Edge D. Providing delirium education for family caregivers of older adults. J Gerontol Nurs 2012; 38: 24-31.

27. Shoemaker SJ, Wolf MS, Brach C. Development of the Patient Education Materials Assessment Tool (PEMAT): a new measure of understandability and actionability for print and audiovisual patient information. Patient Educ Couns 2014; 96: 395-403.

28. Lipari M, Berlie H, Saleh Y, Hang P, Moser L. Understandability, actionability, and readability of online patient education materials about diabetes mellitus. Am J Health Syst Pharm 2019; 76: 182-6.

29. Steis MR, Evans L, Hirschman KB, et al. Screening for delirium using family caregivers: convergent validity of the Family confusion assessment method and interviewer-rated confusion assessment method. J Am Geriatr Soc 2012; 60: 2121-6.

30. Shulman $R W$, Kalra S, Jiang JZ. Validation of the sour seven questionnaire for screening delirium in hospitalized seniors by informal caregivers and untrained nurses. BMC Geriatr 2016; . https://doi.org/10.1186/s12877-016-0217-2.

31. Ely EW, Inouye SK, Bernard GR, et al. Delirium in mechanically ventilated patients: validity and reliability of the confusion assessment method for the intensive care unit (CAM-ICU). JAMA 2001; 286: 2703-10.

32. Ely EW, Margolin R, Francis $J$, et al. Evaluation of delirium in critically ill patients: validation of the confusion assessment method for the intensive care unit (CAM-ICU). Crit Care Med 2001; 29: 1370-9.

33. Abshire M, Dinglas VD, Cajita MI, Eakin MN, Needham DM, Himmelfarb $C D$. Participant retention practices in longitudinal clinical research studies with high retention rates. BMC Med Res Methodol 2017; . https://doi.org/10.1186/s12874-017-0310-z.

34. Robinson KA, Dinglas VD, Sukrithan V, et al. Updated systematic review identifies substantial number of retention strategies: using more strategies retains more study participants. J Clin Epidemiol 2015; 68: 1481-7.

35. Landis $J R$, Koch GG. The measurement of observer agreement for categorical data. Biometrics 1977; 33: 159-74.

36. Gignac GE, Szodorai ET. Effect size guidelines for individual differences researchers. Pers Individ Dif 2016; 102: 74-8.

37. Mailhot T, Cossette S, Côté J, et al. A post cardiac surgery intervention to manage delirium involving families: a randomized pilot study. Nurs Crit Care 2017; 22: 221-8.
38. Otani H, Morita T, Uno S, et al. Usefulness of the leaflet-based intervention for family members of terminally ill cancer patients with delirium. J Palliat Med 2013; 16: 419-22.

39. Gagnon P, Allard P, Gagnon B, Mérette $C$, Tardif $F$. Delirium prevention in terminal cancer: assessment of a multicomponent intervention. Psychooncology 2012; 21: 187-94.

40. Gagnon P, Charbonneau C, Allard P, Soulard C, Dumont S, Fillion L. Delirium in advanced cancer: a psychoeducational intervention for family caregivers. J Palliat Care 2002; 18: 25361.

41. Hughes F, Bryan K, Robbins I. Relatives' experiences of critical care. Nurs Crit Care 2005; 10: 23-30.

42. Azoulay E, Pochard F, Kentish-Barnes N, et al. Risk of posttraumatic stress symptoms in family members of intensive care unit patients. Am J Respir Crit Care Med 2005; 171: 987-94.

43. Soderstrom IM, Saveman BI, Benzein E. Interactions between family members and staff in intensive care units-an observation and interview study. Int J Nurs Stud 2006; 43: 707-16.

44. Vives M, Young L, Sabharwal S. Readability of spine-related patient education materials from subspecialty organization and spine practitioner websites. Spine (Phila Pa 1976) 2009; 34: 2826-31.

45. Eltorai AE, Han A, Truntzer J, Daniels AH. Readability of patient education materials on the American Orthopaedic Society for Sports Medicine website. Phys Sportsmed 2014; 42: 125-30.

46. Paulson CM, Monroe T, McDougall GJ Jr, Fick DM. A familyfocused delirium educational initiative with practice and research implications. Gerontol Geriatr Educ 2016; 37: 4-11.

47. Bannon L, McGaughey J, Clarke M, McAuley DF, Blackwood B. Designing a nurse-delivered delirium bundle: what intensive care unit staff, survivors, and their families think? Aust Crit Care 2018; 31: 174-9.

48. Bohart S, Merete Moller A, Forsyth Herling $S$. Do health care professionals worry about delirium? Relatives' experience of delirium in the intensive care unit: a qualitative interview study. Intensive Crit Care Nurs 2019; 53: 84-91.

49. Bergeron N, Dubois MJ, Dumont M, Dial S, Skrobik Y. Intensive Care Delirium Screening Checklist: evaluation of a new screening tool. Intensive Care Med 2001; 27: 859-64.

50. Aragon Penoyer D. Nurse staffing and patient outcomes in critical care: a concise review. Crit Care Med 2010; 38: 1521-8.

Publisher's Note Springer Nature remains neutral with regard to jurisdictional claims in published maps and institutional affiliations. 